\title{
¿Qué nos insinúa la "experiencia corporal"?
}

What does the "corporal experience" suggests us?

Andrés Díaz Velasco

Resumen

El presente artículo es una reflexión creativa alrededor del concepto "experiencia corporal", concebido como el objeto de estudio de la educación física por el PCLEF (2000). Aborda, en primera medida, las nociones de "experiencia" y de "cuerpo" para dar cuenta de las concepciones que el PCLEF integra en un solo vocablo. En segunda instancia, procura exponer la importancia del concepto en cuanto a la configuración de realidad, la constitución de subjetividad, la construcción y transformación cultural y la práctica educativa en nuestros tiempos modernos.

Palabras clave: Experiencia, cuerpo, vivencia, creencia, sujeto, educación física.

\section{Abstract}

Key words:

The present article is a creative reflection upon the "corporal experience" concept, which the PCLEF (2000) conceives as the object of study of Physical Education. First, it approaches the notions of "experience" and "body", to account for the concepts that the PCLEF integrates in just one word. In the second place, it attempts to present the importance of the concept as for the construction of reality, the building of subjectivity, the construction and cultural transformation and the educational practice in our modern times.

Experience, body, belief, subject, physical education.

\footnotetext{
Estudiante de VI semestre de la Licenciatura en Educación Física Universidad Pedagógica Nacional. Miembro del Colectivo Cuerpo. Este trabajo es fruto de debates entre los miembros del Colectivo y fue esbozado en conjunto con Viviana Betancur Chicué.
} 


\section{Introducción}

\begin{abstract}
Así, pues, nosotros consideramos al organismo como una estructura indivisible de comportamiento cuyas direcciones están unificadas y ordenadas [intencionadas]. El organismo no es jamás un sistema en reposo, sino siempre el centro de una actividad: la necesidad de acción es la necesidad misma de vivir. El comportamiento de un organismo es una actividad global que implica direcciones que poseen el significado que más atrás les hemos dado. Los caracteres y las formas que adquieren las actividades físicas y el movimiento humano están determinados por el marco social. Cada sociedad, mediante la educación que prescribe, impone al individuo un uso determinado del cuerpo.
\end{abstract}

Jean Le Boulch, 1971

A más de cinco años desde que el Proyecto Curricular Licenciatura en Educación Física, PCLEF, de la Universidad Pedagógica Nacional enuncia las alteraciones al currículo universitario y con él sus pretensiones de "formar" un nuevo licenciado, ha pasado como por inercia (aunque no desapercibido) a los salones de clase el grandísimo atrevimiento epistemológico de proponer como objeto de estudio la llamada "experiencia corporal". A pesar de que el concepto es tratado muy superficialmente por la mayoría de actores involucrados, debemos advertir su capital importancia, tanto en lo que refiere al desarrollo epistemológico de la educación física como a su pretensión de "aportar a la solución de problemas, situaciones y cuestionamientos que el nuevo milenio plantea como desafío a las sociedades modernas, desde la comprensión y rescate de la corporeidad como elemento mediador en los procesos de convivencia y construcción de 'ser humano"' (PCLEF, 2004: 12).

Sin duda, el concepto ha generado distintas interpretaciones no sólo por los pocos documentos que ahondan su sentido y apoyan la descripción realizada en el PCLEF $^{1}$, sino por la falta de compromiso de los docentes que muchas veces no leen ni buscan más allá, simplemente dando por hecho que el vocablo solo puede salir a flote en el turbulento océano donde se ampara la disciplinariedad de la educación física. En este sentido, encontramos a veces opiniones convencionales, sobre todo desde el positivismo científico, acerca de la experiencia; encontramos, también, que se le sobrevuela como si no sugiriese algo completamente nuevo (a vuelo de avioneta dice Judith Jaramillo, cofundadora del PCLEF); así mismo, es pensado (y malentendido) como un pleonasmo, como un reforzado término que preten-

\footnotetext{
1 Álvarez Ramírez, Libia y otros. (1998), en el cual se basa el PCLEF.
}

de engañar a algunos cuantos incautos; y la mayoría de las veces se hace referencia a ciertas fenomenologías, las cuales se relacionan con la abusiva e insuficiente categoría de "idealismo".

En el mejor de los casos, simplemente se referencia el libro Sport, expérience corporelle et science de l'homme de Barreau y Morne $(1984)^{2}$, como si estos autores no hubiesen hecho otra cosa que un fabuloso dossier con el propósito de "reunir las fuentes que indiquen las vías de construcción de un concepto" (en 1991: 212), dejando a un lado un verdadero desarrollo epistemológico. No debemos engañarnos, el concepto en el PCLEF está lejos de lo que proponen estos autores, si bien se encuentran algunas relaciones. En primer lugar, Barreau y Morne equiparan las experiencias corporales con las actividades corporales, llamando así al deporte "no más que un tipo" de estas, lo cual ahoga el concepto en sí mismo. Igualmente, dicen que, sin querer hacer una taxonomía exhaustiva, se pueden diferenciar las experiencias corporales que se "presentan como hechos culturales, objetos de transmisión y aprendizaje implícito o explícito" (Ibíd.: 211) de las que no "tienen" cultura alguna, por un lado; y por otro, las de tipo profesional "que suponen la elaboración de secuencias de gestos y movimientos preparados con vistas a prestaciones que entran en un circuito de valores mercantiles" (Ibíd.), de las demás, "ya sea que no entren en este circuito, ya sea que entren pero en este caso no se debe al contenido de la prestación" (Ibíd.); lo que no corresponde con el planteamiento del PCLEF en absoluto, como veremos.

En segundo lugar, los autores franceses ubican como núcleo de la experiencia corporal las "técnicas corporales" de Marcel Mauss, complementándolas -dicen- con la noción usos sociales del cuerpo desarrollada por el sociólogo Luc Boltanski. Sin duda, ambas expresiones son esenciales para comprender la naturaleza y el funcionamiento de las "experiencias corporales", pero es prudente ir más allá y advertir cómo el PCLEF está entrecruzando distintos conceptos como sujeto, diversidad cultural, percepción, vida, huella, contexto, entre otros. Sin embargo, lo que veremos ahora no es un análisis descriptivo sino creativo del concepto. No damos como finalizada ninguna discusión alrededor del mismo, más bien elaboramos algunos argumentos tendientes a desenmascarar aspectos que creemos contenidos en él, a partir de los cuales resaltamos su importancia y la imprescindible tarea de

\footnotetext{
2 Traducido al español como Epistemología y antropología del deporte por Enrique Soto Rodríguez (1991). Madrid: Alianza Editorial-Consejo Superior de Deportes.
} 
continuar con un estudio riguroso ${ }^{3}$. Por ello, no creemos (ni queremos) que el concepto deba ser meramente aceptado o adoptado por los educadores físicos (incluso en la misma Universidad Pedagógica Nacional, aunque suponga cierta institucionalización); estamos lejos, muy lejos de proponer la "universalización" de la educación física, aun si la concebimos como disciplina académica o pedagógica.

\section{De la experiencia y del cuerpo}

El vocablo "experiencia corporal" enlaza tanto la noción de "experiencia" como la de "cuerpo". Por ello, esta conjunción encierra una riquísima magnitud semántica". Resalta tanto la existencia corpórea del ser humano o su dimensión corporal ${ }^{5}$ como sus implicaciones en lo que se considera es el desarrollo del potencial humano, el cual se puede identificar sólo en la medida en que se afirma que el hombre es experienciable corporalmente, y que, como tal, el sujeto es en esencia una experiencia (parafraseando a Hegel: "ex-per-ientia, un 'provenir-de y un ir-a-través-de', recuerda Agamben, en 2001: 42); es decir, aquello que hay de esencial y existencial en el hombre: su cuerpo, necesariamente sufre, a modo de impresiones sucesivas, alteraciones que lo configuran, movilizaciones que lo subjetivan, afecciones que lo habitan y tras-forman continuamente. Por tanto, nos es preciso, aquí y ahora, aproximar aquello que Peter McLaren llama cuerpo-sujeto, esa "forma de ser que se encuentra en nuestros cuerpos" (1993: 91)6.

3 "Lo que se está haciendo no es lo que acaba, aunque tampoco es lo que empieza" (Deleuze y Guattari, 2005: 112).

4 Trataremos en el escrito a la «experiencia corporal» a veces como vocablo, como término, como noción y como concepto no sólo por la comodidad sinonímica, sino porque aún no podemos afirmar que sea propiamente un concepto (Deleuze y Guattari, 2005) y porque nuestra pretensión es tan sólo sugerirlo (parte de lo que esta insinúa).

5 "La dimensión corporal ha sido abordada, por distintas disciplinas que han producido un conjunto de conocimientos para explicar, desde diferentes miradas, los problemas y fenómenos que rodean la existencia corpórea del ser humano. La medicina ha producido un conjunto de saberes sobre prevención, rehabilitación y cuidado en busca de la salud, la prolongación de la vida y el bienestar. La sociología ha explorado teorías sobre el cuerpo como objeto de control, de consumo y como terreno de emancipación. La psicología y la biología han explorado el esquema corporal, la imagen corporal, el talento corporal, el sentido cinestésico y otros puntos de vista antropológicos, filosóficos e históricos que centran su atención en la expresión, la experiencia corporal, la percepción, la sensibilidad y la comunicación. En el campo de la educación, se han elaborado diferentes prácticas y discursos sobre la salud, la higiene, la disciplina y el orden, la postura, la convivencia social, la educación de los sentidos, el rendimiento físico, la recreación, el desarrollo motriz, la sexualidad y la inteligencia corporal" (Lineamientos curriculares en educación física, 2000: 25-26).

6 El terreno de la carne en el que el significado se inscribe, se construye y se reconstruye. La superficie intermedia entre el individuo y la sociedad;

\section{¿Cuál es la "experiencia" de la experiencia corporal?}

En sentido estricto, leemos en el Diccionario de filosofía, existen distintas nociones de experiencia:

1. La aprehensión por un sujeto de una realidad, una forma de ser, un modo de hacer, una manera de vivir, etc. La experiencia es entonces un modo de conocer algo inmediatamente antes de todo juicio formulado sobre lo aprehendido.

2. La aprehensión sensible de la realidad externa. Se dice entonces que tal realidad se da por medio de la experiencia, también por lo común antes de toda reflexión.

3. La enseñanza adquirida con la práctica. Se habla entonces de la experiencia en un oficio y en general, de la experiencia de la vida.

4. La confirmación de los juicios sobre la realidad por medio de una verificación, por lo usual sensible, de esta realidad. Se dice entonces que un juicio sobre la realidad es confirmable, o verificable, por medio de la experiencia.

5. El hecho de soportar o "sufrir" algo, como cuando se dice que experimenta un dolor, una alegría, etc. (Ferrater, 2001: 1181)

Incuestionablemente, el vocablo "experiencia" se usa en varios sentidos, aunque hay algo común en ellos; precisamente,

el hecho de que se trate de una impresión inmediata por un sujeto de algo que se supone "dado". [De este modo] se pueden subrayar dos sentidos primordiales: a) la experiencia como confirmación, o posibilidad de confirmación empírica de datos, y b) la experiencia como hecho de vivir algo dado anteriormente a toda reflexión o predicación. En cada uno de estos casos se puede destacar el carácter "externo" o "interno" de la experiencia (Ferrater, 2001: 1181).

Estas características, externa e interna, de la "experiencia” están saldadas en la expresión "experiencia corporal" y, a su vez, aquello que se adquiere no como efecto, sino como "ganancia-logro"; es lo que la constituye o compone. Sin embargo, lo inmediato de la experiencia no consiste en alguna clase de "uniformidad en su esencia” como diría Gaston Bachelard, más bien se trata de la aprehensión sensible que no tiene ni intermediarios ni

lugar de la subjetividad incorporada o "encarnada" que también refleja las sedimentaciones ideológicas de la estructura social inscrita en él. Forma de una intencionalidad socialmente inscrita (McLaren, 1993: 87). 
funciona causalmente. He aquí la relación experienciavivencia: la "experiencia" no será la misma vivencia; su diferencia consiste en que no todo lo vivido es una experiencia, aunque esta se dé solo y únicamente durante la otra.

La vivencia es la duración-calidad, para hablar como Bergson; esa transición continua, esa homogénea y no matemática percepción del tiempo, ese flujo fenomenológico:

Según Dilthey, la vivencia es un modo de existir la realidad para un cierto sujeto. La vivencia no es, pues, algo dado; somos nosotros quienes penetramos en el interior de ella, quienes la poseemos de una manera tan inmediata que hasta podemos decir que ella y nosotros somos la misma cosa. Por vivencias en el más amplio sentido del vocablo, dice Husserl, entendemos "todo lo que encontramos en el flujo de lo vivido y, por lo tanto, no sólo las vivencias intencionales, las cogitaciones actuales y potenciales, tomadas en su entera concreción, sino también las que se presentan como momentos reales en este flujo y sus partes concretas" (Ferrater, 2001: 3713-3714).

Si bien la experiencia se presenta indudablemente a diario, su mecanismo es más cuantitativo, más psicológico, para seguir con Bergson y Husserl. La experiencia permite que materialicemos la vivencia, que a pesar de su fluidez inconsciente permanezca en nosotros un algo: posibilidad del pensamiento, posibilidad del lenguaje, posibilidad de conocimiento... Tal es la importancia de la experiencia en la ciencia, y veremos entonces porqué Bachelard la piensa como "unidad" aún en su racionalismo activo; pero, la ciencia delimita la experiencia por comodidad del estudio, en el fondo, la separa de su verdadera esencia y la utiliza de otro modo. Al respecto Giorgio Agamben (1978) se esfuerza por rescatar la experiencia de la ciencia (y del mundo moderno), redimiendo lo que llama la experiencia tradicional separada de la ley científica, la psique del nous. Ya lo decía Bergson: "la conciencia, atormentada por un insaciable deseo de distinguir, substituye el símbolo por la realidad, o no percibe la realidad más que a través del símbolo" (en 1977: 11).

Hay, pues, una gran diferencia: la "experiencia corporal" no remite ni a la experiencia pura, atribuida por Agamben a la "duración pura" de Bergson y a la "experiencia vivida/interna" de Dilthey (que estamos diferenciando ${ }^{7}$ ); ni a la experiencia muda, pre-lingüística

7 Entre otros, según el Diccionario de filosofía, Walter Benjamin, German Nohl, George Simmel, han distinguido entre vivencia (Erlebnis) y expe- o pre-predicativa, propia de la fenomenología. Si bien estas nociones le acompañan o le sirven como proximidades, no la definen. Además, tampoco refiere a la "experiencia ordenada" (Bacon) o experimento, propio de las pretensiones científicas. La "experiencia corporal" no pretende tanto un distanciamiento de la ciencia o la filosofía como una explicación concreta de la construcción de sentidos (subjetividad y cultura). Por tanto, hemos de reconocer como dos cosas distintas vivencia y experiencia corporal. La inmediatez de la experiencia no es la misma inmediatez de la vivencia; si la palabra es la misma, lo que quieren decir no lo es. En fin, "se entiende la vivencia como un contacto en el cual el que posee la vivencia posee al mismo tiempo el objeto de la vivencia, de modo que 'vivencia de' y 'objeto de vivencia' se hallan fundidos" (Ferrater, 2001: 3713). Es así como en el proceso que es vivir, el cuerpo sensible-sentido aprehende la realidad vivida en la medida en que experimenta (o experiencia, si se prefiere). De este modo, la experiencia corporal es "esporádica" no "constante"; no es absoluta (no existen ni el sujeto ni la cultura absolutos) sino relativa; la experiencia de la experiencia corporal permite al cuerpo-sujeto (lingǘstico) diferenciarse del objeto (visible y enunciable) en la medida en que sucede por impresiones (capturas-aprehensiones).

De este modo, la "experiencia corporal" como movimiento o actividad, no es algo solidificado e infranqueable, no es un conjunto estático de impresiones. La experiencia corporal es una sucesión animada de percepciones distintas, heterogéneas. Nos acercamos, pues, a la concepción que tenía Hume acerca de la experiencia (que podemos relacionar con el hábito), atravesando el empirismo y la subjetividad, como demuestra Deleuze a propósito del filósofo inglés:

La experiencia es la sucesión, el movimiento de las ideas separables en la medida en que son diferentes, y diferentes en la medida en que son separables. De esta experiencia hay que partir porque es la experiencia. No supone nada más y nada la antecede. Por una parte Hume nos presenta a la experiencia como un principio que manifiesta una multiplicidad, una repetición de casos semejantes; literalmente, es un principio que afecta al tiempo con un pasado. Y por otra parte ve en el hábito otro principio, que nos determina a pasar ahora de un objeto al que lo acompañaba, es decir, que organiza al tiempo como un presente perpetuo al que debemos y podemos adaptarnos (Deleuze, 2002: 94-104). 
En este sentido, hemos también de distinguir la experiencia de la creencia (o conocimiento, del que decía Hume depende de la unión entre experiencia y hábito). No se trata tanto de cierta "permeabilidad" de la razón a la experiencia, como solemos pensarla, sino de una diferencia de naturaleza. (Siguiendo el anterior análisis de Deleuze, la creencia no sólo no comienza con la experiencia sino además no deriva de ella). Al respecto, la sociología del conocimiento ha cruzado ya tales senderos; decimos, entonces, que la "experiencia corporal" se presenta durante la vivencia del "cuerpo-hombre", y habilita la configuración de la creencia, pero no la determina, no la origina, no la establece.

Apoyarse en la hipótesis de que la facultad perceptiva es relativamente estable, no impide decir que sus aportaciones no constituyen -ni pueden constituir- conocimiento, lo cual se debe a que la experiencia siempre tiene lugar sobre un estado anterior de creencias. Ella es una de las causas que puede provocar alteraciones en ese estado de creencias, de modo que el nuevo estado resultante siempre será el resultado de una componenda entre la reciente influencia y el estado precedente. Esto significa que la experiencia puede provocar cambios pero que por sí sola no determina el estado de creencia. Una manera de representarse este proceso es establecer una analogía con el efecto de una fuerza que incide sobre un sistema de fuerzas, esta fuerza influirá en la fuerza resultante, pero no será la única en hacerlo. Cualquier valor de la componente experiencial no se corresponde con un único valor de la creencia resultante, si antes no se ha fijado el estado previo de creencias. Hay que tener esto siempre en cuenta cuando se piense en el efecto que producirá una experiencia. Así mismo, ningún patrón o secuencia de experiencias cambiantes determinará por sí mismo un patrón único de cambio en las creencias. No hay nada de extraño en que el simple hecho de observar el mundo no nos conduzca a ponernos de acuerdo sobre cuál debe ser la verdadera descripción que debamos dar a él. La misma experiencia conlleva reacciones diferentes al enfrentarse con diferentes sistemas de creencias (Bloor, 1998: 70-71).

Por ello, para no engañarnos, la vivencia, la experiencia (como experiencia corporal) y la creencia no se suceden de forma procesual, no son consecuencia una de otra, son más bien procesos paralelos, simultáneos de la configuración corporal de quien existe. Su diferencia es de naturaleza: la vivencia es homogénea y absoluta, la experiencia es heterogénea y mutable, y la creencia es virtual.

\section{¿Cuál es el "cuerpo" de la experiencia corporal?s}

Ahora bien, en cuanto al cuerpo se refiere, para el PCLEF es imprescindible dar cuenta de su disposición biológico-cultural, de modo que podamos acercarnos a lo que implica su anexión en la conjunción que estamos tratando. Sin duda, tras un análisis biológico, el "cuerpohombre" no solo está constituido materialmente como los demás seres de la naturaleza, sino que también posee diferencias anatómicas y morfológicas que le posibilitan interactuar con el "medio" de manera particular, digamos, como ninguna otra especie. Por un lado, es el "cuerpo electro-químico" donde se producen las sensaciones, aquel que conecta, comunica, relaciona, vincula; el cuerpo del micromovimiento, decía Cagigal (1979); se trata del receptáculo (cavidad y fuente) de los estímulos sensoriales.

Hay terminaciones nerviosas sensitivas especializadas (receptores), los cinco sentidos y la cinestesia. Existen líneas transmisoras que conducen el impulso desde los receptores hacia el SNC. Existe la unión o plexo del SNC en donde se unen las neuronas aferentes y eferentes. Existen las líneas de transmisión que llevan el impulso desde el SNC hasta los órganos efectores. $Y$, existen músculos que ejecutan la respuesta apropiada (Barrow y Brown, 1992: 120).

Y por otro, es el "cuerpo-físico" en el espacio y en el tiempo lo que configura la condición "cuerpo-hombre", tanto en sentido morfológico como psicológico, tanto en sentido geográfico como histórico. Se trata del cuerpo y sus movimientos reales: "la mano nos proporciona valiosos datos sobre las características y propiedades de los objetos (forma, peso, consistencia, temperatura, etc.) facilitando así la adaptación y coordinación de nuestros movimientos en relación con el mundo exterior" (Meinel, 1998: 18). De igual forma, sabemos que "la posición vertical modificó la relación coste-beneficio de recoger, transportar y utilizar herramientas para realizar tareas que el cuerpo no podía realizar" (Harris, 1992: 40).

Es así, como en el proceso evolutivo, tanto por el desarrollo de su sistema nervioso como por el del tracto oral, gracias al cual es posible todo "sistema fonético", y por la adopción del bipedismo, que permite hacer un

8 Tratamos indiferentemente las nociones cuerpo, corporeidad y corporalidad, que tanto debate han producido.

9 El sistema fonético de determinada lengua consta de conjuntos de voces que son inconscientes $y$ arbitrariamente percibidos por el que habla como contrastados. La estructura del sistema fonético de una determinada lengua [es] su sistema de contraste de sonidos (Harris, 1998: 73). 
uso de las manos diferente al de desplazarse, el "cuerpohombre" despega culturalmente.

La capacidad humana para la cultura es un resultado de los procesos evolutivos biológicos, de los cuales el de mayor importancia es el conocido como selección natural. Esta tiene lugar como consecuencia de la capacidad reproductora de la vida, potencialmente infinita, y la naturaleza real y finita del espacio y la energía de los que depende. La selección natural actúa sobre las unidades básicas de la herencia, los genes, localizados en las células reproductoras de todos los organismos. Actúa aumentando o disminuyendo la frecuencia de las variantes genéticas, cuya fuente principal son las mutaciones-«errores» que ocurren durante el proceso de replicación de los propios genes. La selección natural no sólo moldea la anatomía y fisiología de los organismos; también puede influir en las características de su conducta (Harris, 1998: 34-36).

Esta es una visión materialista de la cultura, es decir, no solo se le entiende como "fabrica de significados" parte del "mundo de las Ideas" sino como modos socialmente aprendidos de pensar y comportarse, y por tanto no es una "posesión" exclusiva del hombre aunque, gracias a su cuerpo, este haya podido complejizarla, desplegarla, variarla: "una vez que la capacidad para la cultura se desarrolló completamente, un vasto número de diferencias y semejanzas culturales pudo surgir y desaparecer de forma completamente independiente de cambios en los genotipos" (Harris, 1998: 44). En este sentido, es cierto que "las variaciones culturales se imponen sobre un estrato de capacidades sensoriales biológicamente [y relativamente] estables" (Bloor, 1998: 70).

De este modo, la condición biológica del "cuerpohombre" no puede aislarse de su condición cultural; la dicotomía naturaleza-cultura (u hombre-naturaleza) ya no puede ser entendida como una simple relación conflictiva entre lo que al hombre se le presenta o le es "dado naturalmente" (para que utilice a su acomodo) y lo que el hombre "inventa" gracias a su capacidad racional superior: ni lo que supuestamente le es dado le parecería como tal fuera de sus interpretaciones y significaciones culturales, ni lo que crea para intervenir su realidad proviene de una separación de lo que puede saber de la naturaleza. Lo que interpreta del mundo natural que lo rodea, al cual está unido indefectiblemente (tanto por las llamadas necesidades naturales, como la alimentación y la respiración, como por su composición atómica si se quiere hablar como un físico-químico moderno, o similar a Leibniz y a Demócrito), no lo hace de forma distanciada e independiente a lo que observa.
El hombre es un sentir-sentido: organiza el caos-natural relacionando su cuerpo con el mundo-entorno (donde está siendo, donde se mueve: nuestro cuerpo es parte integrante del mundo exterior, decía Nietzsche) ${ }^{10}$.

En esto concluyeron, con mucha precisión, las investigaciones de Carlos Pinzón y Rosa Suárez:

Cada cultura construye la concepción del cuerpo sobre la base de una relación homológica en la cual, el macrocosmos, la organización social, la distribución de los espacios culturales y la actividad económica predominante, son reproducidos de una manera sintetizada e integral por el cuerpo o microcosmos" (1992: 46).

Se trata, pues, de comprender que la cultura es natural: "la selección natural y la evolución orgánica se encuentran en la base de la cultura" (Harris, 1998: 44); $y$, por tanto, el "cuerpo-hombre" es un cuerpo biológicocultural o, sencillamente, siguiendo a Pinzón y Suárez, un "cuerpo cultural".

De modo similar, afirma el filósofo italiano Sante Babolin

el hombre en su concreta existencia produce cultura porque tiene un cuerpo: la diversidad de respuestas de dos individuos, de la misma edad y del mismo sexo, puestos en las mismas condiciones de un ecosistema, a un mismo estímulo depende casi completamente de su diferente corporeidad (2005: 60).

De este modo, las mismas explicaciones que hemos presentado anteriormente pertenecen a un "contexto cultural" particular, del cual hacemos parte de forma habitual; nos arriesgamos a usar palabras como "receptáculo" y "sensación", entre otras, a pesar de sus diversas interpretaciones con el único fin de exponer con cierta coherencia el hecho de que podamos hacer lecturas diferentes del cuerpo y del mundo; sin embargo, no tienen necesariamente que arrastrarnos al relativismo extremo del "todo vale" o "nada importa". Las reflexiones que actualmente se producen entorno a la diversidad como campo natural en el que se pueden identificar las diferencias sin excluirlas, esconderlas, borrarlas, etc., es un campo fértil para entender la importancia de lo diferen-

10 Otro sentido que desbarata la distinción hombre-naturaleza es la presentada por Deleuze y Guattari en El Anti-Edipo, evocando lo que significó Marx como "producción" ("todo es producción"): "La esencia humana de la naturaleza y la esencia natural del hombre se identifican en la naturaleza como producción o industria, es decir, en la vida genérica del hombre. Hombre y naturaleza no son como dos términos uno frente al otro (...) son una misma y única realidad esencial del productor y del producto. La producción como proceso desborda todas las categorías ideales y forma un ciclo que remite al deseo en tanto que principio inmanente" (1995: 14). Producción deseante natural en el hombre como parte de la naturaleza infinitamente productora (Homo natura). 
te en cuanto a la convivencialidad. De allí, que el PCLEF sea intrínsecamente intercultural, ya que comprende que los "acuerdos" no son dados por una universalidad de la capacidad perceptiva (biológica si se quiere), sino por el diálogo, por el lenguaje interactuante.

Finalmente, toda "experiencia corporal" hace confluir necesariamente las cualidades biológica y cultural del cuerpo, es decir, no se puede pensar en una experiencia sino en un "cuerpo-sentido", la experiencia corporal sólo es posible en tanto el ser que existe percibe, en tanto está-siendo-en-el-mundo, en tanto se mueve físicamente (es este el sentido de estar educado físicamente en el PCLEF, de ningún modo un simple desarrollo de habilidades físicas y motrices). De este modo, aproximarse al re-conocimiento del ser humano desde la educación física del PCLEF, "implica pensarlo como hombre-cuerpo, como hombre-experiencia corporal, es decir, como esa conjunción compleja y profunda entre naturaleza y cultura que le permite interconstituirse socioculturalmente" (PCLEF, 2004: 31).

\section{Experiencia corporal y educación física}

Podemos aproximarnos a lo que se quiere decir con la expresión "experiencia corporal": primero, la experiencia corporal refiere al cuerpo "uno-múltiple", es decir, al cuerpo individual (no independiente) compuesto por las fuerzas que lo cruzan: físico-químicas, animales, políticas, sexuales, lingüísticas... ${ }^{11}$; a su vez, la experiencia corporal remite o relaciona la vivencia y la creencia sin confundirse con ninguna ni determinarlas; es el dispositivo del sentido en la medida en que "atrapa" o "abraza" lo sensible como correlato del significado. La "experiencia corporal" es un puente entre cierto sí-mismo (uno) y cierto Otro (múltiple), es la conductibilidad existencial, ya que la subjetividad no es un estado interior distante de un exterior, sino la conjunción de lo Uno y lo Otro ${ }^{12}$.

\footnotetext{
${ }^{11}$ A propósito de Nietzsche, comenta Deleuze (1967): "cualquier relación de fuerzas constituye un cuerpo: químico, biológico, social, político. Dos fuerzas cualesquiera, desiguales, constituyen un cuerpo a partir del momento en que entran en relación: por eso el cuerpo... aparece siempre como la cosa más "sorprendente", mucho más sorprendente realmente que la conciencia y el espíritu. El cuerpo es un fenómeno múltiple, al estar compuesto por una pluralidad de fuerzas irreductibles; su unidad es la de un fenómeno múltiple. Cualquier realidad ya es... cantidades de fuerza, 'en relación de tensión' unas con otras" (en 2002b: 60).

12 "Decir algo en nombre propio es muy curioso, porque no es en absoluto en el momento en el que uno se toma por un yo, una persona o un sujeto, cuando se habla en su nombre. Al contrario, un individuo adquiere un verdadero nombre propio como consecuencia del más severo ejercicio de despersonalización, cuando se abre a las multiplicidades que le atraviesan de parte a parte, a las intensidades que le recorren" (Deleuze, "Lettre a M. Creéosle" o "Carta a un crítico severo". En Conversaciones 1972-1990.
}

Que toda experiencia es corporal, es un hecho indudable, pero lo que se reitera con el aditivo "corporal" como forma del concepto es, precisamente, la totalidad de la experiencia en la totalidad de la existencia: esa aprehensión real mutable que no es ni la integración de redes nerviosas aparentemente independientes, ni la depuración lingüístico-racional de la supuesta superioridad humana, sino la interacción-modificación total (biológico-cultural) entre cuerpos. La experiencia corporal es el cuerpo en relación o interacción ${ }^{13}$. La experiencia corporal no es simplemente la suma porcentual de las entradas sensibles (exteroceptividad-interoceptividad-propioceptividad) sino la "apropiación-captura" recíproca entre el cuerpo (desde la punta de los pies incluso con zapatos) y el circunstancial entorno (en) que este (se) sitúa.

La "experiencia corporal" es el re-conocimiento de nuestro cuerpo: "la memoria que nuestro cuerpo tiene del modo en que nuestros músculos deben moverse, del modo en que nuestros brazos deben oscilar y nuestras piernas andar" (McLaren 1993: 91). Hay una experiencia que permite nuestra constitución como sujetos y le llamamos experiencia corporal.

No sorprende, luego, que la definición sugerida por el PCLEF sea como sigue:

La experiencia corporal (en el marco de cualquier cultura y sociedad) puede ser asumida como el conjunto de impresiones que dejan huella y dan lugar a la asignación de significado particular y construye la historia de vida de cada persona, pero que puede reconstruirse y modificarse a partir de los acontecimientos sociales y culturales que lo afecten en su totalidad (PCLEF, 2004: 30)

Desarrollemos o desenvolvamos estas palabras. "Conjunto de impresiones" sugiere dos análisis complementarios: por un lado, el conjunto no es la suma sino la unión, reunión, agrupación o colección de elementos distinguibles entre sí y definidos o especificados; por otra, los elementos pertenecen o están contenidos en

(1995), traducción de José Luis Pardo. Valencia: Pre-textos), La subjetividad, como "Cinta de Moebio", decía el educador físico argentino Ricardo Crisorio en el marco del Seminario Internacional de Epistemología y Enseñanza de la Educación Física, octubre de 2007, Bogotá, Universidad Pedagógica Nacional. Sin duda, el adentro como pliegue del afuera: "la subjetivación se hace por plegamiento” (Deleuze, 1987: 137). Véanse los cuatro pliegues.

13 Aleccionador ver cómo incluso la psicología comportamental se apega tanto a la interacción, rechazando las incongruencias del "fantasma en la máquina”. Arturo Clavijo (2006): "la psique no es un evento trascendental sino un fenómeno que se caracteriza por la interacción permanente y mutua entre cierta clase de sistemas, que incluye a los animales (humanos y no humanos), con el ambiente del cual forman parte", p.13. 
el conjunto de modo tal que éste es un todo, pero no uniforme sino múltiple, un conjunto es una multiplicidad consistente, siguiendo a Georg Cantor (1845-1918), creador de la teoría de los conjuntos matemáticos. Sin embargo el "conjunto", que es la experiencia corporal, no supone una "estructura" u "organización" según ciertas reglas o funciones causales, predecibles y binarias; por el contrario, su figuración es rizomática, y en cuanto tal es creativa ${ }^{14}$. Veremos, por tanto, cómo y por qué es posible que se "reconstruya" $y$ "modifique".

Así mismo, las "impresiones" no son ideas independientes del sentir o sensaciones ausentes de significado (meramente fisiológico), no son una representación cerebral o mental proveniente de estímulos sensoriales, y tampoco son la suma de tales impulsos nerviosos; estas son un "sistema de fuerzas" que se componen, incitan e intensifican entre ellas, en el que no encontramos solamente impresiones visuales o auditivas, sino impresiones emocionales y pasionales (significaba Hume las impresiones como "todas nuestras percepciones más vivaces cuando oímos o vemos o palpamos u odiamos o deseamos o queremos" citado en Ferrater, 2001:1784).

Las impresiones se presentan de forma vivaz, en el flujo de lo vivido, en el flujo de lo sentido, y no son objetos o puntos relacionables sino una colección, o la relación misma. Contracción de vibraciones, vibraciones contraídas: sensación como contemplación pura en

14 "A diferencia de los árboles o de sus raíces, el rizoma conecta cualquier punto con otro punto cualquiera. El rizoma pone en juego regímenes de signos muy distintos e incluso estados de no-signos. El rizoma no se deja reducir ni a lo Uno ni a lo Múltiple. No es lo Uno que deviene dos, ni tampoco que devendría directamente tres, cuatro o cinco, etc.; no es un múltiple que deriva de lo Uno, o al que lo Uno se añadiría. No está hecho de unidades, sino de dimensiones, o más bien de direcciones cambiantes. No tiene ni principio ni fin, siempre tiene un medio por el que crece y desborda. Constituye multiplicidades lineales de $\mathrm{n}$ dimensiones, sin sujeto ni objeto, distribuibles en un plan de consistencia del que siempre se sustrae lo Uno. Una multiplicidad de este tipo no varía sus dimensiones $\sin$ cambiar su propia naturaleza y metamorfosearse. Contrariamente a una estructura, que se define por un conjunto de puntos y de posiciones, de relaciones binarias entre estos puntos y de relaciones biunívocas entre esas posiciones, el rizoma sólo está hecho de líneas: líneas de segmentaridad, de estratificación, como dimensiones, pero también línea de fuga y de desterritorialización como dimensión máxima según la cual, siguiéndola, la multiplicidad se metamorfosea al cambiar de naturaleza. Lo fundamental es que el árbol-raíz y el rizoma-canal no se oponen como dos modelos: uno actúa como modelo y como calco trascendente, incluso si engendra sus propias fugas; el otro actúa como proceso inmanente que destruye el modelo y esboza un mapa, incluso si constituye sus propias jerarquías, incluso si suscita un canal despótico. No se trata, pues, de tal o tal lugar de la tierra, ni de un determinado momento de la historia, y mucho menos de tal o tal categoría del espíritu, sino del modelo que no cesa de constituirse y desaparecer, y del proceso que no cesa de extenderse, interrumpirse y comenzar de nuevo. ¡No seáis ni uno ni múltiple, sed multiplicidades! El rizoma tiene como tejido la conjunción 'y...y...y'” (Deleuze y Guattari, 1997: 25)
Deleuze y Guattari (1991): “es por contemplación como uno contrae... contemplar es crear" (2005: 213).

De allí, lo cierto de que "el sujeto y el objeto dan una mala aproximación del pensamiento. Pensar no es un hilo tensado entre un sujeto y un objeto, ni una revolución de uno alrededor del otro" (Deleuze y Guattari, 2005: 86). Subjetividad y pensamiento como impresión subyacen en el concepto "experiencia corporal"; concebimos que "la idea no es la representación de un objeto, sino la representación de una impresión" (Deleuze, 2002: $95)^{15}$. Si la relación de los objetos estuviese después de su percepción (pensar=estructurar), no solo cada objeto no se entendería realmente sino que no podría darse una idea de ninguno; en la impresión no priman objeto y fondo independientemente sobre su relación o comprensión. Una naranja, por ejemplo, no se siente amarilla, redonda y grande, independiente de la manzana roja, la mesa cuadrada y la pequeña ciruela. Como en los cuadros de Manet, lo que prima es una impresión, separable sí de otras impresiones. Las impresiones son sustanciales.

Así mismo las impresiones, como elementos del conjunto, pueden ser distinguidas y definidas a partir del modo en que se moviliza o es movilizado el cuerpo de la acción; "qué regiones del cuerpo se movilizan y qué tipos de disciplina son impuestas sobre esta movilización para producir el alma de un héroe, un santo o un perfecto cortesano" preguntaba Feher (1990: 14).

En este sentido, es posible que se den las impresiones: no existe pasividad alguna mientras se percibe, ni siquiera lo ojos pueden quedarse quietos para enfocar, siempre hay movimiento, y la visión envejece en cada nuevo minuto. De este modo, "impresiones que dejan huella" no debe concebirse como una redundancia. Si bien se ha entendido por "impresión" la producción de una huella, en el caso de la "experiencia corporal", esta última constituye la modificación del cuerpo que se mueve y mientras se mueve.

Si arriba dijimos que las impresiones eran fuerzas en relación (relaciones de poder) ahora será del movimiento del cuerpo de que dependerán para ser concebidas como tal. No hay acción que no sea una fuerza; todo cuerpo que se mueve es un cuerpo marcado, impresionado, sentidamente subjetivado. El movimiento es ejer-

\footnotetext{
${ }^{15}$ La crítica que hace Deleuze a la representación no es pertinente para este escrito, lo que ahora nos interesa es mostrar cómo la relación sujeto-objeto es sólo una de las posibles lecturas que sobre la construcción de conocimiento y constitución de realidad existen. Así mismo, es importante anotar que el concepto que estamos tratando tiende a distanciarse sustancialmente de esta relación.
} 
cicio de poder y estas fuerzas constituyen modos de subjetividad que permiten, una vez más, que distingamos la vivencia de la experiencia corporal, y comprendamos las "huellas" de las "impresiones" como afectos.

El único objeto de la fuerza son otras fuerzas, y su único ser la relación. Cada fuerza tiene a la vez un poder de afectar (a otras) y de ser afectada (por otras), por eso implica relaciones de poder. Un ejercicio de poder aparece como un afecto, puesto que la propia fuerza se define por su poder de afectar a otras. Incitar, suscitar, producir constituyen afectos activos, y ser incitado, ser suscitado, ser obligado a producir, tener un efecto "útil", constituyen afectos reactivos. Estos no son simplemente "la consecuencia" o el "reverso pasivo" de aquellos, sino más bien el "irreductible opuesto". Espontaneidad y receptividad adquieren ahora un nuevo sentido: afectar, ser afectado (Deleuze, 1987: 99-100).

El hecho de que la experiencia corporal da "lugar a la asignación de significado particular y construye la historia de vida de cada persona" implica dos situaciones: primero, todo sentir es al mismo tiempo un significado; el sentido no es el efecto de la razón, sino aquello en lo que estamos inmersos, sumergidos, instalados; el cuerpo está situado en el sentido y no hay sentido que no sea un sentirse, por ello, el sentido es particular y lo que es bueno, útil, especial, amable, decible, comible... para uno, puede no serlo para otro. De allí que el PCLEF afirme que la experiencia corporal es "intransferible, única o irrepetible" (2004: 30).

Segundo, el cuerpo-uno particulariza o singulariza lo otro-múltiple en la medida en que se mueve en el espacio, lugariza el espacio y otorga su sentido personal a las impresiones que lo marcan, es decir, las marcaciones no suceden de forma pasiva, no se ejercen sobre cuerpos de cera, sino que tienen lugar sobre cuerposmúltiples movibles, y los sentidos no dependen de cavidades indiferentes o naturalmente neutrales, no son procesos llegados a su fin, sino creados. De este modo, la "historia de vida de cada persona" no es la consecución de estados corporales temporalmente lineales, sino el devenir-acontecimiento donde el cuerpo se sitúa azarosamente ${ }^{16}$.

\footnotetext{
${ }^{16}$ La otra "historia de vida", esa que no es "narrada", que no tiene forma de "relato". Una historia que se ha introducido en la literatura (Proust, Artaud, Blanchot), en la filosofía (Foucault, Klossowski), y en la misma Historia ("científica"). Por parte de la sociología, Bourdieu será ahora nuestro mejor ejemplo: "esta vida organizada como una historia (en el sentido de relato) se desarrolla, según un orden cronológico que es así mismo un orden lógico, desde un comienzo, un origen, en el doble sentido de punto de partida, de inicio, pero así mismo de principio, de razón de ser, de causa primera, hasta su término que es también un fin, una realización (telos).
}

\section{Por ello, el PCLEF expresa que}

la experiencia corporal tiene lugar en la confluencia del sujeto, el Otro y el contexto sin que este proceso sea unívoco, ni obedezca a una relación causa-efecto. [Lo que] permite que simultáneamente se den la universalidad de la experiencia humana, la diversidad cultural y la singularidad del sujeto (PCLEF, 2004: 31) ${ }^{17}$.

\section{Por ello,}

la verdad es que se cambia sin cesar, y que el estado mismo es ya cambio. Es decir que no hay diferencia esencial entre pasar de un estado a otro y persistir en el mismo estado. Tengo frío o calor, estoy alegre o triste, trabajo o no hago nada, miro lo que me rodea o pienso en otra cosa. Sensaciones, sentimientos, voliciones, representaciones, tales son las modificaciones en que se reparte mi existencia y que la colorean alternativamente (Bergson, 1977: 7-8).

En esto consiste el hecho de que la experiencia corporal "puede reconstruirse y modificarse a partir de los acontecimientos sociales y culturales que lo afecten [al hombre] en su totalidad [cuerpo]". De allí que Foucault haya afirmado

que el problema a la vez político, ético, social y filosófico que hoy se nos plantea no es tratar de liberar al individuo del Estado y de sus instituciones, sino liberarnos nosotros del Estado y del tipo de individualización que este conlleva. Debemos promover nuevas formas de subjetividad rechazando el tipo de individualidad que se nos ha impuesto durante siglos (2005: 41).

\footnotetext{
[Pero esta es una ilusión retórica, porque (citando a Alain Robbe-Grillet] 'lo real es discontinuo, formado por elementos yuxtapuestos sin razón, cada uno de los cuales es único, tanto más difíciles de captar cuanto que surgen de manera siempre imprevista, sin venir a cuento, aleatoria"' (1997: 75-76). Sin duda, no solo nos hemos "acostumbrado" a pensar nuestras vidas según una serie ordenada y secuencial de "hechos" (yo, él, ellos, con nombres propios y fechas), sino que se nos facilita, hasta cierto punto, dar cuenta de la vida de los demás de ese modo; el docente se explica por tal método el comportamiento de sus estudiantes, habla así de sus "historias de vida".

17 "Sabemos ahora que lo que llamamos leyes naturales son verdades meramente estadísticas que deben, por tanto, necesariamente, dejar margen a las excepciones. Si dejamos las cosas a merced de la naturaleza, cada proceso se ve interferido de forma parcial o total por el azar. Las consideraciones teóricas sobre causa y efecto a menudo resultan desviadas e imprecisas en comparación con los resultados prácticos del azar" (Jung, 1949, prólogo al I-Ching). "No se cometa el error de hacer condicionados la causa y el efecto, como acontece a los naturalistas y a los que siguen su método, a los cretinos mecanicistas, los cuales quieren que la causa pugne hasta producir un "efecto". En el in se [sí mismo] no hay "nexos causales", no hay "necesidad", no hay "determinismo psicológico"; allí el "efecto" no es una consecuencia de la "causa"; allí no manda ninguna ley" (Nietzsche, 2000: 38-39).
} 
Por ello, no motricidad, así sencillamente, sino relaciones de poder: se trata de acciones que se modifican (marcan, dejan huella) y crean sujetos:

El ejercicio del poder no es simplemente una relación entre parejas, individual o colectiva, es una forma en la que ciertas acciones modifican otras. Lo que define una relación de poder es que es un modo de acción que no actúa directa o indirectamente sobre otros. En cambio actúa sobre sus acciones; una acción sobre una acción, sobre acciones existentes o sobre aquellas que pueden surgir en el presente o en el futuro. Es una forma de poder que hace a los individuos sujetos (Ibíd.: 36, 44-45) ${ }^{18}$.

He aquí el poder de la educación física (en la escuela): movilización directa de los cuerpos. Y, a su vez, la importancia de introducir la experiencia corporal como conćepto, parte fundamental de su disciplinariedad y de su transformación. Ahora bien, existe otra reflexión paralela para dar cuenta de esta importancia: se trata de comprender cómo las experiencias corporales pueden atravesar el "tiempo" y constituirse como memoria ${ }^{19}$, ya no transferible, de modo que cada cual tenga, por decirlo así, una misma experiencia corporal, si no transmisible.

Pero, lo que se transmite no es una memoria, cada cual "tiene" en su cuerpo el pasado que (le) pesa. No se puede transmitir propiamente una experiencia corporal (estas no se pueden medir ni categorizar, no son suscep-

18 "Existen dos significados de la palabra sujeto: sujeto a alguien por el control y la dependencia, y el de ligado a su propia identidad por una conciencia o autoconocimiento. Ambos significados sugieren una forma de poder que subyuga y crea sujeto para" (Foucault, 2005: 36). Esta subjetividad es propia de la vida de Occidente. Descubierta, según Foucault, por los griegos (hombres libres), se metamorfosea, cambia de modo "históricamente". Desde el siglo XVI, el Estado como una forma de poder en "progreso" promueve una forma de subjetividad que nos individualiza y totaliza a la vez. Lo mismo que el poder disciplinario de la escuela (del cual aún no podemos decir que hemos salido sino que estamos saliendo) normaliza e individualiza a los estudiantes. Lo que hay de fondo es el hecho de que el cuerpo-uno es aquello que se subjetiva (parte material de nosotros mismos: primer pliegue); por ello, la pregunta que plantea Deleuze en torno a la subjetivación, según Foucault, es ¿qué puedo ser... cómo producirme como sujeto?

${ }^{19}$ Ya nos hemos referido a la memoria de la forma de movernos en McLaren; ahora estamos aproximando la noción expresada por Deleuze en su texto sobre Foucault: "memoria es el verdadero nombre de la relación consigo mismo o del afecto de sí por sí mismo. El plegamiento, el redoblamiento, es una memoria: "absoluta memoria" o memoria del afuera. El tiempo como sujeto, o más bien subjetivación, se llama memoria. No esa corta memoria que viene después, y que se opone al olvido, sino la "absoluta memoria" que dobla el presente, que redobla el afuera y que se identifica con el olvido, puesto que ella misma es sin cesar olvidada para ser rehecha. Sólo el olvido (el despliegue) encuentra lo que está plegado en la memoria (en el propio pliegue). Lo que se opone a la memoria no es el olvido, sino el olvido del olvido que nos disuelve en el afuera, y que constituye la muerte. Por el contrario, mientras el afuera está plegado, existe un adentro coextensivo a él, como la memoria es coextensiva al olvido. Es esta coextensividad la que es vida, periodo largo" (1987: 140-141). tibles de taxonomía). Lo que se transmite son prácticas, movimientos imitables, movimientos que se aprenden, actividades de producción, de comunicación, de diversión, etc. Lo que permite que permanezca cierta "continuidad" de experiencias corporales, o que haya cierta similitud en las mismas, es que se heredan "condiciones" de realización de las acciones y formas concretas de acción (técnicas, hábitos, prácticas). Entonces, la forma en la que se pueden transmitir las experiencias corporales es muy simple: hay que hacer lo que se hacía antes.

Son múltiples los factores, mecanismos, circunstancias e instituciones que han afectado en menor o mayor grado la adquisición de diversas prácticas corporales, que dentro del proceso de culturización y socialización implícito contienen el acumulado de la experiencia construida por las generaciones que anteceden a las nuevas, en su proceso de civilización; es a partir de las experiencias (que son corporales) como el ser humano ha transmitido y enseñado a las siguientes generaciones sus hábitos, creencias, ritos, mitos, valores y normas, generando con ello diversas acciones, prácticas, símbolos y significados que traducen su impresión en expresiones y comunicaciones corporales (PCLEF, 2004: 30).

Lo decía Lévi-Strauss a propósito de Marcel Mauss: "la estructura social imprime su sello sobre los individuos por medio de la educación de las necesidades y actividades corporales" (1950: 14). Sin duda, "tenemos cuerpos no solo porque hemos nacido en cuerpos, sino porque aprendemos nuestros cuerpos, esto es, se nos enseña cómo pensar nuestros cuerpos y cómo experimentarlos" (McLaren, 1993: 93). Por tanto, estaremos de acuerdo en que "toda sociedad se ha propuesto construir el cuerpo que sus circunstancias naturales y sociales requieren" (PCLEF, 2004: 14). A través, nada menos, que de la movilización.

La revisión de la historia humana a partir de la observación de sus hechos y prácticas sociales, evidencia la evolución de prácticas corporales que suponen la elaboración de gestos y movimientos, con la intención de dar respuesta a exigencias del medio y a la construcción de valores socioculturales, que tienen como insumo las experiencias colectivas desarrolladas en cada grupo (PCLEF, 2004: 30).

Por tanto, volvemos a que "la cultura se inscribe tanto sobre el cuerpo como en él" (McLaren, 1993:91). En efecto, "es precisamente a través del cuerpo singular como la vida de un pueblo se perpetúa" (Mopsik en Feher, 1990: 49). En este sentido, cada cultura ha instaurado, a través de su historia, prácticas (cotidianas o no) en las que se "adquieren" experiencias corporales 
que identifican y cohesionan a los sujetos. Las sociedades "asignan" las "condiciones" que pueden perpetuar ciertas experiencias corporales, aquellas que permiten la continuidad de aspectos culturales, "Ta continuidad de creencias', consciente e inconscientemente (¿qué hubiesen sido las "conquistas" sin la imposición de prácticas foráneas al conquistado?).

Justamente, en este sentido, la educación física del PCLEF, proyecta su intervención social educativa, es decir, adquiere un carácter pedagógico; ya sea para reconocer (investigar) los procesos educativos que se llevan a cabo en las diferentes culturas, ya sea para construir currículos propios (o contextualizados). Por ello, son preguntas primordiales: cómo se representa su "papel" la experiencia corporal en la relación enseñanza-aprendizaje; en el proceso de desarrollo del cuerpo-niño al cuerpo-adulto y de este a la "muerte"; en el proceso de "transmisión", "asimilación" y "transformación" de las prácticas que "codifican" el modo de "moverse" en el "mundo" generación tras generación.

Comprendamos que el PCLEF no rechaza el deporte para nada, no lo ve como un medio ideológico y comportamental del capitalismo industrializado a secas; intuye que hay algo más que puede preguntarse (quizá desde su disciplinariedad): ¿qué experiencias corporales configuran qué sujetos y qué culturas a través de las prácticas deportivas? ¿Acaso se trata de sujetos competitivos, clasificados y clasificadores; sujetos "conquistadores"; sujetos disciplinados, dóciles, acaso automatizados; sujetos que piensan sólo en sus intereses personales? ¿ Son posibles los sujetos solidarios en las prácticas deportivas, cómo, por qué? Y del mismo modo se pregunta: ¿qué experiencias corporales configuran qué sujetos y qué culturas a través de las danzas; a través de las prácticas laborales de oficina, del cultivo de la tierra, de la pesca y la caza; a través de prácticas como las cirugías (plásticas o propiamente médicas), el tatuaje, el sicariato, la elección política, la guerra...?

De este modo,

al asumir la reflexión de la experiencia corporal como objeto de estudio del PCLEF se propone además de reconocer el conjunto histórico de las prácticas corporales y culturales en la sociedad, identificar y construir los procesos que hacen de la experiencia corporal un factor determinante de la construcción de la dimensión corporal que imprime singularidad y particularidad al sujeto social y cultural (PCLEF, 2000: 30-31).

\section{Conclusión: más allá de la educación física}

La "experiencia corporal" más que la posibilidad de un concepto es la materialización de la vivencia a partir de las modificaciones a las acciones del cuerpo-uno por otros cuerpos y de este sobre los otros; es, por tanto, aquella que posibilita modos de subjetividad, construcción de culturas y configuración de realidades. De esta manera, se da solo y únicamente en la interacción; es en la interacción-movimiento-modificación donde tienen lugar las experiencias corporales. Sin duda, es la concreción de las singularidades socioculturales, en y por el cuerpo, lo que no significa que el sujeto sea fijo, eterno e independiente sino que es construido por lo otro (el afuera: su pliegue). La "experiencia corporal" precisamente da cuenta de la imposibilidad de un cuerpopropio aislado y conformado por cierta interioridad y lo denota como una composición singularizada o singularizadora de lo otro, conformado sólo y únicamente por aquello en lo que está en relación.

Entonces, el "hombre" mientras "está-siendo-en-elmundo", como existente, es experienciado y experiencia$b l e, y$ en tanto tal es una conjugación entre lo que fue y lo que no ha sido: está entre lo que está-siendo, es una síntesis entre el futuro y el pasado. Por tanto, la experiencia corporal "constituye" en un presente infinitivo (donde cobran relevancia no sólo la cotidianidad sino el tiempo de clase) la formación y trans-formación de los "cuerpos-hombres". En consecuencia es necesario un análisis más profundo, de largo aliento, acerca de los distintos elementos y momentos del proceso en el que son dadas las experiencias corporales. En tal estudio es menester contar con las proximidades y componentes del concepto, entre los cuales podemos apenas señalar la "sensación-percepción", la “emoción", la "invención", la "transmisión", la "adquisición-asimilación", el "conocimiento", la "conciencia", entre otras.

Como expresamos al principio, lo que nos propusimos con este escrito fue apenas una aproximación creativa al concepto (la pregunta es ¿qué nos insinúa...?); por ello, realizamos este tejido no sólo para dar cuenta de los entrecruzamientos conceptuales (que rompen las referencias fenomenológicas), sino para resaltar su importancia más allá de la educación física. UD 


\section{Bibliografía}

Agamben, Giorgio. (2001). Infancia e Historia. Destrucción de la experiencia y origen de la historia. Del original de 1978, Infanzia e storia. Argentina: Adriana Hidalgo Editora.

Álvarez Ramírez, Libia y otros. (1998). Experiencia Corporal. Tesis Especialista en Pedagogía y Didáctica de la Educación Física. Bogotá: Universidad Pedagógica Nacional, Facultad de Educación Física.

Babolin, Sante. (2005). Producción de sentido. Bogotá: Universidad Pedagógica Nacional-San Pablo.

Bachelard, Gaston. (1973). Epistemología. Textos escogidos por Dominique Lecourt. Del original de 1971, Épistémologie. Barcelona: Anagrama.

Barreau, J-J. y Morne, J-J. (1991). Epistemología y antropología del deporte. Del original de 1984. Madrid: Alianza Editorial.

Barrow, Harold y Brown, Janie. (1992). Hombre y movimiento. Barcelona: Editorial Doyma.

Bergson, Henri. (1977). Memoria y vida. Textos escogidos por Gilles Deleuze. Madrid: Alianza Editorial.

Bloor, David. (1998). Conocimiento e imaginario social. Barcelona: Gedisa.

Cagigal, José María. (1979). Bases antropofilosóficas para una educación física. En Cultura Intelectual y cultura física. Buenos Aires: Editorial Kapelusz.

Bourdieu, Pierre. (1997). Razones prácticas. Sobre la teoría de la acción. Del original de 1994. Barcelona: Anagrama.

Clavijo, Arturo. (2006). Más allá del fantasma en la máquina. Bogotá: Universidad Nacional de Colombia, Facultad de Ciencias Humanas, Departamento de Psicología-Siglo del Hombre Editores.

Deleuze, Gilles. (2002). Empirismo y subjetividad. Barcelona: Gedisa.

Deleuze, Gilles. (2002b). Nietzsche y la filosofía. Del original de 1967, Nietzsche et la philosophie. Barcelona: Anagrama.

Deleuze, Gilles. (1987). Foucault. Barcelona: Paidós Ibérica.

Deleuze, Gilles y Guattari, Félix. (2005). ¿Qué es la Filosofía? Del original de 1991, Quest-ce que la philosophie? Barcelona: Anagrama.

Deleuze, Gilles y Guattari, Félix. (1995). El Anti-Edipo. Capitalismo y esquizofrenia. Del original de 1972. España: Ediciones Paidós Ibérica.

Deleuze, Gilles y Guattari, Félix. (1997). Mil mesetas. Capitalismo y esquizofrenia. Del original de 1980. Valencia: Pre-Textos.

Ferrater Mora, José. (2001). Diccionario Filosófico. Barcelona: Editorial Ariel.
Feher, Michel. (1990). Fragmentos para una historia del cuerpo humano. Primera parte. Madrid: Taurus.

Foucault, Michel. (2005). El sujeto y el poder. En Pensamiento y experimentación. Bogotá: Carpe Diem.

Harris, Marvin. (1992). Nuestra Especie. Madrid: Alianza Editorial.

Harris, Marvin. (1998). Antropología Cultural.Madrid: Alianza Editorial.

Jung, C. G. (1949). Prólogo de I Ching. El libro de las mutaciones. Versión del Chino al alemán por Richard Wilhelm, traducido al español por D. J. Vogelman. Bogotá: Editorial Solar.

Le Boulch, Jean. (1982). Hacia una ciencia del movimiento Humano: introducción a la Psicokinetica. Del original de 1971.Buenos Aires: Paidós.

Lévi-Strauss, Claude. (1950). Sociología y Antropología. Introducción a la obra de Marcel Mauss. La Habana: Editorial Semilla y Surco. Colección de Ciencias Sociales.

MEN. (2000).Lineamientos curriculares de Educación Física. Bogotá: Ministerio de Educación Nacional.

Marleau-Ponty, Maurice. (1977). El ojo y el espíritu. Buenos Aires: Paidós.

McLaren, Peter. (1993). Formación escolar del cuerpo posmoderno: pedagogía crítica y política de encarnación. En Pedagogía crítica, resistencia cultural y la producción del deseo. Argentina: Rei Argentina-Aique.

Meinel, Kurt. (1998). Didactica del Movimiento: ensayo de una teoría del movimiento en el deporte desde el punto de vista pedagógico. La Habana: Orbe.

Mopsik, Charles. El cuerpo del engendramiento en la biblia hebráica, en la tradición rabínica y en la cábala. En Feher, Michel. (1990). Fragmentos para una historia del cuerpo humano. Madrid: AlteaTaurus-Alfaguara.

Morales y Peña. (2004). Líneas de Investigación Facultad de Educación Física. Bogotá: Universidad Pedagógica Nacional.

Nietzsche, F. (2000). Más allá del bien y del mal. Madrid: Editorial Libsa.

PCLEF. (2004). Jaramillo Judith y otras. Facultad de Educación Física Universidad Pedagógica Nacional. Bogotá.

Pinzón Castaño. Carlos E. y Suárez Prieto. Rosa (1992) Las Mujeres lechuza. Bogotá: Instituto Colombiano de Antropología e Historia, ICANH, y CEREC. 